\title{
Resolvin E1 Inhibits Osteoclastogenesis and Bone Resorption by Suppressing IL-17-induced RANKL Expression in Osteoblasts and RANKL-induced Osteoclast Differentiation
}

\author{
Yoshihiro Funaki, Yasuyuki Hasegawa, Ryota Okazaki, Akira Yamasaki, Yuriko Sueda, Akihiro Yamamoto, \\ Masaaki Yanai, Takehito Fukushima, Tomoya Harada, Haruhiko Makino and Eiji Shimizu \\ Division of Medical Oncology and Molecular Respirology, Department of Multidisciplinary Internal Medicine, School of Medicine, \\ Tottori University Faculty of Medicine, Yonago 683-8504, Japan
}

\begin{abstract}
Background Resolvin E1 (RvE1) derived from the $\omega-3$ polyunsaturated fatty acid eicosapentaenoic acid is known to be a potent pro-resolving lipid mediator that prevents chronic inflammation and osteoclastogenesis. We investigated the inhibitory effects of RvE1 on osteoclastogenesis and bone resorption to clarify its therapeutic potential for rheumatoid arthritis (RA).

Methods Receptor activator of nuclear factor- $x \mathrm{~B}$ ligand (RANKL)-induced osteoclast differentiation was assessed with tartrate-resistant acid phosphatase staining. RANKL-induced bone resorption was assessed by the measurement of pit formation using calcium phosphate-labeled fluorescent polyanionic molecules in RAW264.7 cells as osteoclast precursors. The effects of RvE1 on the RANKL-induced mRNA expression of osteoclast-specific genes and transcriptional factors such as c-fos and nuclear factor of activated T cells c1 (NFATc1) in RAW264.7 cells were measured by quantitative real-time PCR. The distribution of NFATc1 induced by RANKL was evaluated by immunofluorescence staining in RAW264.7 cells. To analyze the mechanism of the inhibitory effect of RvE1 on osteoclastogenesis, we measured IL-17-induced RANKL mRNA expression in MC3T3-E1 osteoblast cells treated with RvE1 using quantitative real-time PCR and determined the level of prostaglandin $\mathrm{E}_{2}\left(\mathrm{PGE}_{2}\right)$ production by enzyme-linked immunosorbent assay.
\end{abstract}

Results RvE1 significantly suppressed RANKL-in-

Corresponding author: Yasuyuki Hasegawa, MD, PhD

hasechi@med.tottori-u.ac.jp

Received 2017 November 27

Accepted 2017 December 21

Abbreviations: BLT1, leukotriene B4 receptor subtype 1; COX, cyclooxygenase; EPA, eicosapentaenoic acid; ELISA, enzyme-linked immunosorbent assay; DHA, docosahexaenoic acid; FBS, fetal bovine serum; IL, interleukin; mPGES-1, microsomal prostaglandin E synthase-1; MMP, matrix metalloproteinase; NFATc1, nuclear factor of activated T cells c1; OPG, osteoprotegerin; PBS, phosphate-buffered saline; PGE2, prostaglandin E2; PUFA, polyunsaturated fatty acid; RANKL, receptor activator of nuclear factor- $x \mathrm{~B}$ ligand; RvE1, resolvin E1; TNF, tumor necrosis factor; TRAP, tartrate-resistant acid phosphatase duced osteoclast differentiation and bone resorption. RvE1 inhibited the RANKL-induced mRNA expression of osteoclast-specific genes along with the transcription factors NFATc1 and c-fos. Moreover, NFATc1 translocation from the cytoplasm to the nucleus of RAW264.7 cells was suppressed following RvE1 treatment. RvE1 also inhibited IL-17-induced RANKL mRNA expression and $\mathrm{PGE}_{2}$ production in MC3T3-E1 cells.

Conclusion RvE1 inhibited osteoclastogenesis and bone resorption by suppressing RANKL-induced NFATc1 and c-fos expression in osteoclasts and IL-17induced RANKL expression through the autocrine action of $\mathrm{PGE}_{2}$ in osteoblasts. Our data suggest RvE1 as a new therapeutic target of RA.

Key words interleukin-17; osteoblasts; osteoclasts; RANK ligand; resolvin E1

The bone undergoes continuous remodeling to achieve a balance between bone formation and resorption mediated by osteoblasts and osteoclasts, respectively. Rheumatoid arthritis (RA) is a chronic inflammatory autoimmune disease characterized by progressive synovial inflammation and destruction of the joint cartilage and bone. ${ }^{1}$ In particular, RA involves a breakdown of metabolic balance in the bone, and is characterized by an increase in bone resorption that results in impaired bone formation. ${ }^{2}$ This imbalance is caused by the increase of various inflammatory cytokines, including receptor activator of nuclear factor- $x \mathrm{~B}$ ligand (RANKL) and its competitive inhibitor osteoprotegerin (OPG), in the inflammatory tissue., ${ }^{3,4}$ Thus, anti-inflammatory drugs are most commonly prescribed to treat the symptoms of RA. However, recent evidence points to the beneficial effects of natural compounds on reducing inflammatory cascades, providing new options for RA treatment.

For example, a diet enriched in $\omega-3$ polyunsaturated fatty acids (PUFAs) was found to reduce joint stiffness in the morning and the number of tender joints, ${ }^{5}$ and also decreased the levels of inflammatory cytokines in the blood, including tumor necrosis factor-alpha (TNF- $\alpha$ ), 
interleukin (IL)-1 $\beta$, and IL-6. 6,7 Indeed, several randomized clinical studies have revealed that dietary supplementation with $\omega-3$ PUFAs is efficacious in reducing joint pain, the duration of morning stiffness, the number of tender or swollen joints and non-steroidal anti-inflammatory drug usage in RA patients. ${ }^{8}{ }^{9}$ However, the mechanisms of these clinical effects of $\omega-3$ PUFAs have remained unclear. Recent discoveries demonstrate that $\omega-3$ PUFAs such as eicosapentaenoic acid (EPA) and docosahexaenoic acid (DHA) can be enzymatically converted in vivo to novel bioactive lipid mediators termed specialized pro-resolving mediators, including resolvins, protectins and maresins, which promote the resolution of inflammation and have more potent effects than their lipid precursors. ${ }^{10}$

One of the specialized pro-resolving mediators derived from EPA, resolvin E1 (5S, 12R, 18R-trihydroxy-6Z, 8E, 10E, 14Z, 16E-eicosapentaenoic acid; RvE1), was originally identified in exudates of the murine dorsal air pouch, an acute inflammation model. ${ }^{11}$ Recent findings demonstrated that RvE1 had protective effects in periodontal disease, ${ }^{12}$ peritonitis, ${ }^{13}$ asthmatic airway inflammation, ${ }^{14}$ bacterial pneumonia and acute lung injury in vivo. ${ }^{15}$ Accordingly, we speculated that the same bone-protective effects noted in periodontal disease might be applicable to RA. There have been only a few reports on the regulation of RvE1 for bone resorption and osteoclast differentiation, ${ }^{16}$ and the effects and mechanism of RvE1 on bone remodeling are still not fully understood. Therefore, in this study, we originally investigated the effects of RvE1 on the inflammation and signaling pathways in osteoclasts and osteoblasts to provide a foundation for RvE1 as a new therapeutic approach in RA treatment. Our results are the first to indicate that RvE1 interacts with osteoclasts and osteoblasts via inhibition of RANKL production in osteoblasts.

RANKL is a member of the TNF superfamily of cytokines and is known to induce osteoclastogenesis from monocytes or macrophages. The binding of RANKL to its receptor RANK, expressed on osteoclast precursors, induces the expression and/or activation of transcription factors, including nuclear factor of activated $\mathrm{T}$ cells $\mathrm{cl}$ (NFATc1) and c-fos, which have been shown to be essential for osteoclast differentiation. . $^{17}, 18$

Pro-inflammatory molecules play a significant, but primarily indirect, role in osteoclast regulation as they act through modulating RANKL and OPG. ${ }^{19}$ TNF $\alpha$, IL-1, IL-6, IL-11 and IL-17 act on osteoblasts and bone marrow stromal cells to increase RANKL and/ or decrease OPG expression in osteoblasts. ${ }^{20,21} \mathrm{IL}-17$ is a pro-inflammatory cytokine induced by a subset of $\mathrm{T}$ helper 17 cells. ${ }^{3,22}$ In osteoblasts, RANKL is induced by prostaglandin $\mathrm{E} 2\left(\mathrm{PGE}_{2}\right)$, which is in turn strongly induced by IL-17; however, this $\mathrm{PGE}_{2}$-induced upregulation of RANKL expression could be inhibited by NS398, a selective cyclooxygenase-2 (COX-2) inhibitor. ${ }^{3,23}$ Thus, IL-17 indirectly induces osteoclastogenesis via $\mathrm{PGE}_{2}$-induced RANKL expression in osteoblasts and has been implicated in the promotion of the pathogenesis of RA. Based on this background, in this study, we focused on the potential effects of RvE1 on mediating IL-17induced osteoclastogenesis to alleviate the inflammation associated with RA. We further examined the potential mechanism underlying the effects of RANKL, IL-17 and/or RvE1 in RAW264.7 and mouse MC3T3-E1 cells as osteoclasts and osteoblasts, respectively. We examined the effect on osteoclastogenesis by determining the expression of matrix metalloproteinase-9 (MMP-9) and cathepsin $\mathrm{K}$, which are highly expressed in osteoclastic cells and considered as markers of mature osteoclasts that play important roles in osteolysis. ${ }^{24} \mathrm{PGE}_{2}$ production tends to be induced by endogenous COX-2 and microsomal PGE synthase-1 (mPGES-1). Therefore, the COX-2 and mPGES-1 mRNA expression levels were examined with real-time PCR, and the production level of $\mathrm{PGE}_{2}$ was examined with an enzyme-linked immunosorbent assay (ELISA) in MC3T3-E1 cells to understand the mechanism of the inhibitory effects of RvE1 on osteoclastogenesis. Osteoblasts are involved in osteoclast regulation by expressing RANKL on their membranes or releasing it as a soluble factor. ${ }^{2}$ We therefore further verified the mRNA expression of RANKL and its competitive inhibitor OPG in MC3T3-E1 cells by real-time PCR. Together, these in vitro results could provide a foundation for the clinical application of RvE1 in maintaining the balance of bone metabolism and in the treatment or prevention of RA.

\section{MATERIALS AND METHODS Cell culture and reagents}

RAW264.7 cells were purchased from American Type Culture Collection (Manassas, VA) and were used as osteoclastic cells. Mouse calvarial cells (MC3T3-E1) were purchased from the RIKEN BioResource Center (Tsukuba, Japan) and were used as osteoblastic cells. RAW264.7 cells were cultured in Dulbecco's minimal essential medium (D-MEM; Wako Pure Chemicals, Osaka, Japan) containing $10 \%$ fetal bovine serum (FBS), $100 \mu \mathrm{g} / \mathrm{mL}$ penicillin and $100 \mu \mathrm{g} / \mathrm{mL}$ streptomycin. MC3T3-E1 cells were cultured in $\alpha$-MEM (Wako Pure Chemicals) containing 10\% FBS, $100 \mu \mathrm{g} / \mathrm{mL}$ penicillin and $100 \mu \mathrm{g} / \mathrm{mL}$ streptomycin. Both cell lines were cultured at $37{ }^{\circ} \mathrm{C}$ in a humidified $5 \% \mathrm{CO}_{2}$ atmosphere. RAW264.7 cells were cultured with or without 
Table 1. Primers for real-time PCR

\begin{tabular}{llllc}
\hline Genes & Assay ID & RefSeq & $\begin{array}{l}\text { Exon } \\
\text { Boundary }\end{array}$ & $\begin{array}{c}\text { Product } \\
\text { length (bp) }\end{array}$ \\
\hline NFATc1 & Mm00479445_m1 & NM_00116409.1 & $7-8$ & 75 \\
c-fos & Mm00487425_m1 & NM_010234.2 & $1-2$ & 59 \\
Cathepsin K & Mm00484039_m1 & NM_007802.4 & $7-8$ & 73 \\
MMP-9 & Mm00442991_m1 & NM_013599.3 & $5-6$ & 80 \\
RANKL & Mm00441906_m1 & NM_011613.3 & $2-3$ & 66 \\
OPG & Mm00435454_m1 & NM_008764.3 & $4-5$ & 71 \\
COX-2 & Mm00478374_m1 & NM_011198.3 & $5-6$ & 80 \\
mPGES-1 & Mm00452105_m1 & NM_022415.3 & $2-3$ & 87 \\
GAPDH & Mm99999915_m1 & NM_001289726.1 & $2-3$ & 107
\end{tabular}

COX-2, Cyclooxygenase-2; GAPDH, glyceraldehyde-3-phosphate dehydrogenase; MMP-9, matrix metalloproteinase-9; mPGES-1, microsomal prostaglandin E synthetase-1; NFATc1, nuclear factor of activated T cells c1; OPG, osteoprotegerin; RANKL, receptor activator of nuclear factor $\chi \mathrm{B}$ ligand. a: TaqMan Gene Expression Assay (Applied Biosystems)

soluble RANKL (Oriental Yeast, Tokyo, Japan) and RvE1 (Toronto Research Chemicals, Toronto, Canada). MC3T3-E1 cells were cultured with or without IL-17 (Pepro Tech, Rocky Hill, NJ) and RvE1.

\section{Cell proliferation assay}

Cell viability was assessed using Cell Counting Kit-8 (CCK-8; Dojindo, Kumamoto, Japan). RAW264.7 and MC3T3-E1 cells were seeded in 96-well plates at $5.0 \times$ $10^{3}$ cells/well in D-MEM or MEM- $\alpha$ each containing $10 \%$ FBS. Following incubation for $24 \mathrm{~h}$, the cells were treated with $0,50,100$ or $200 \mathrm{nM}$ RvE1. After $1 \mathrm{~h}$, the cells were treated with $100 \mathrm{ng} / \mathrm{mL}$ RANKL (RAW 264.7 cells) or $50 \mathrm{ng} / \mathrm{mL}$ IL-17 (MC3T3-E1 cells). After $24 \mathrm{~h}, 10 \mu \mathrm{L}$ CCK-8 solution was added to the culture and the cells were further incubated in the dark at $37{ }^{\circ} \mathrm{C}$ for $2 \mathrm{~h}$. The plate was then read using a Sunrise microplate analyzer (Tecan, Mannedorf, Switzerland) at 450 $\mathrm{nm}$ with a reference at $600 \mathrm{~nm}$. The number of surviving cells was quantified by measuring the absorbance at this wavelength.

\section{Tartrate-resistant acid phosphatase (TRAP) stain- ing}

RAW264.7 cells were plated in 24-well microplates at a density of $1.0 \times 10^{4}$ cells $/ \mathrm{mL}$ and left overnight to settle. Conditioned medium containing 50 or $100 \mathrm{ng} / \mathrm{mL}$ soluble RANKL was then added to the cells and cultured for 6 days. On day 7 of culture, the cells were fixed and stained using a TRAP staining kit (Wako Pure Chemicals) according to the manufacturer's instructions. The number of osteoclast-like cells per well was then counted (TRAP-positive cells with more than three nuclei). Each experiment was performed in duplicate.

\section{Quantitative real-time PCR}

Total RNA was isolated from cultured cells using the RNeasy Plus mini kit (Qiagen, Valencia, CA) according to the manufacturer's instructions. The mRNA was reverse-transcribed into cDNA using the Super Script VILO Master Mix (Invitrogen, Carlsbad, CA) and the resultant cDNA was subjected to real-time PCR using the TaqMan Fast Advanced Master Mix (Applied Biosystems, Carlsbad, CA). Specific primers (Table 1) were purchased from Applied Biosystems (Foster City, CA). PCR was performed using the TaKaRa PCR Thermal Cycler Dice system (Takara Bio, Kusatsu, Japan) under the following conditions: initial holding at $25^{\circ} \mathrm{C}$ for $10 \mathrm{~min}$ and then $42.0^{\circ} \mathrm{C}$ for $60 \mathrm{~min}$ and finally $85.0{ }^{\circ} \mathrm{C}$ for $5 \mathrm{~min}$. Real-time PCR was performed on a ViiA7 Real-Time PCR system (Applied Biosystems) for 40 cycles of $95{ }^{\circ} \mathrm{C}$ for $1 \mathrm{~s}$ and $60^{\circ} \mathrm{C}$ for $20 \mathrm{~s}$. The expression levels of NFATc1, c-fos, cathepsin K, MMP-9, RANKL, OPG, COX-2 and mPGES-1 were normalized to that of glyceraldehyde 3-phosphate dehydrogenase (GAPDH). All real-time PCR experiments were performed in triplicated and analyzed by the comparative $2-\Delta \Delta \mathrm{Ct}$ relative quantification method.

\section{Immunofluorescence staining}

RAW264.7 cells were cultured in glass chamber slides (Lab-Tek II Chamber Slide w/Cover RS Glass Slide Sterile; Nalge Nunc) for $24 \mathrm{~h}$ with or without RANKL plus RvE1. The glass chamber slides were then removed, washed in phosphate-buffered saline (PBS), fixed with 4\% paraformaldehyde for $20 \mathrm{~min}$, permeabilized with $0.5 \%$ TritonX-100 for $1 \mathrm{~h}$, incubated with bovine serum albumin for $1 \mathrm{~h}$ to block non-specific binding and then incubated with mouse NFATc1 monoclonal antibody (diluted 1:50; Santa Cruz Biotechnology, Dallas, TX) overnight at $4{ }^{\circ} \mathrm{C}$. The cells were washed again in PBS and incubated with Alexa Fluor 488 goat anti-mouse secondary antibody (diluted 1:2000; Life Technologies, Carlsbad, CA) for $1 \mathrm{~h}$. The nuclei of cells were stained using the blue fluorescent dye 4',6-diamidino-2-phenylindole in Vectashield mounting medium (Vector Laboratories, Burlingame, CA). Images were obtained with a confocal microscope (TCS-SP2 confocal microscope; Leica, Wetzlar, Germany).

\section{Bone resorption assay}

The bone resorption assay was performed using Bone 
Resorption Assay Kit 24 (PG Research, Kodaira, Japan). ${ }^{25}$ First, $0.5 \mathrm{~mL}$ fluorescein amine-labeled chondroitin polysulfate (Bone Resorption Assay FACS) was added to each well of a calcium phosphate-coated 24well plate (Bone Resorption Assay 24) and incubated at $37{ }^{\circ} \mathrm{C}$ in a humidified $5 \% \mathrm{CO}_{2}$ atmosphere for $2 \mathrm{~h}$ under a light-shielded condition. After the incubation, each well of the 24-well plate was washed with $1 \mathrm{~mL}$ PBS twice and then $1 \mathrm{~mL}$ MEM- $\alpha$ without phenol red (Wako Pure Chemicals) containing 10\% FBS was added. The RAW264.7 cells were inoculated into each well at a density of $1.0 \times 10^{4}$ cells $/ \mathrm{mL}$ and allowed to attach for 4 $\mathrm{h}$ before being treated with 50 or $100 \mathrm{nM} \mathrm{RvE1}$ for $1 \mathrm{~h}$, followed by incubation with 10-200 ng/mL RANKL for 6 days without a medium change. RvE1 and RANKL were added at the same dose after 3 days. After 6 days, $100 \mu \mathrm{L}$ of the culture supernatant from each well was harvested into a 96-well plate and mixed with $50 \mu \mathrm{L}$ of $0.1 \mathrm{~N} \mathrm{NaOH}$ (Bone Resorption Assay Buffer). The flu- orescence intensity of the culture supernatant was measured using a fluorescence plate reader (Infinite F500, Tecan, Mannedorf, Switzerland) with an excitation wavelength of $485 \mathrm{~nm}$ and emission wavelength of 535 $\mathrm{nm}$. The remaining plates were washed with PBS and treated with 5\% sodium hypochlorite for $5 \mathrm{~min}$. After washing the plates with water and drying them, the pit area was photographed by a fluorescence microscope (BZ-8100, Keyence, Osaka, Japan).

\section{ELISA}

The amount of $\mathrm{PGE}_{2}$ in the culture medium was determined using a commercially available ELISA kit (Enzo Life sciences, Farmingdale, NY) according to the manufacturer's instructions, and the data were converted to $\mathrm{pg} / \mathrm{mL}$. Finally, duplicate assays were performed on each sample, and the absorbance at $405 \mathrm{~nm}$ was recorded.

(A)

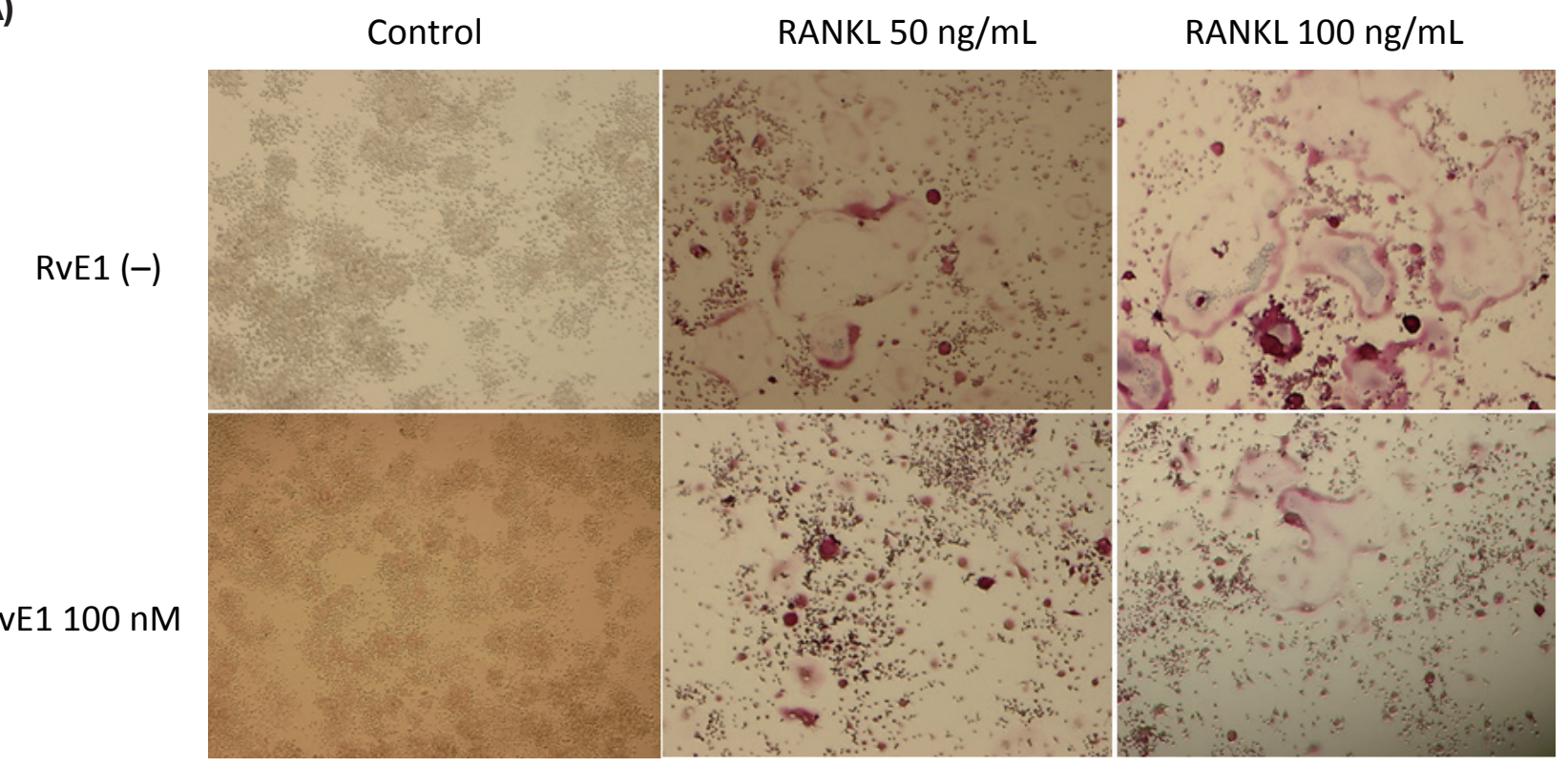

(B)

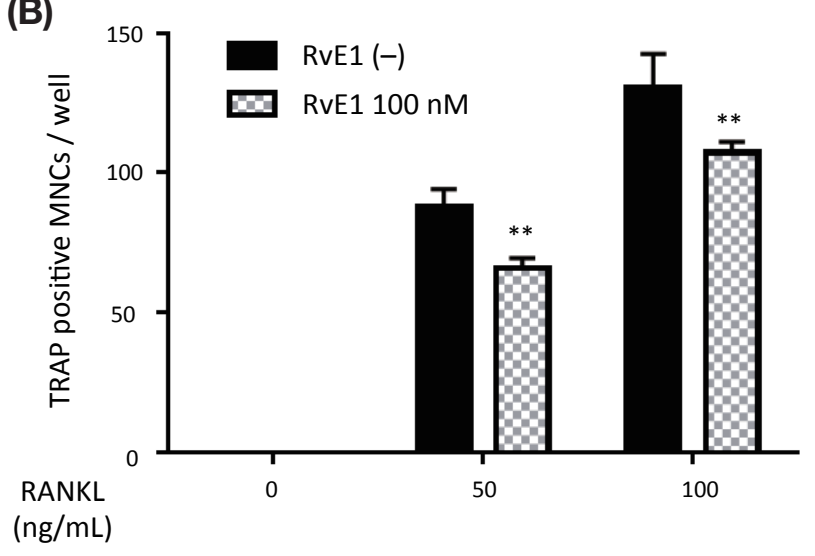

Fig. 1. Effects of RvE1 on the number of TRAP-positive osteoclast-like RAW264.7 cells.

RAW264.7 cells were cultured in conditioned medium containing 50 or $100 \mathrm{ng} / \mathrm{mL}$ RANKL with or without $100 \mathrm{nM} \mathrm{RvE1} \mathrm{for}$ 6 days. Osteoclast-like cells were stained by TRAP on day 7 of culture. Representative microscope images are shown. Original magnification, $\times 100$ (A). The number of TRAP-positive multinucleated cells in the conditioned medium treated with $100 \mathrm{nM}$ RvE1 was significantly reduced compared to groups treated with both 50 and $100 \mathrm{ng} / \mathrm{mL}$ RANKL (B). Data are expressed as the mean $\pm \mathrm{SD}(n=3)$. $* * P<0.01$ versus RvE1 $(-)$ in the presence of 50 or $100 \mathrm{ng} / \mathrm{mL}$ RANKL. MNC, multinucleated cell; RANKL, receptor activator of nuclear factor- $\chi \mathrm{B}$ ligand; $\mathrm{RvE1}$, resolvin $\mathrm{E} 1$; TRAP, tartrate-resistant acid phosphatase. 


\section{(A)}

RANKL $10 \mathrm{ng} / \mathrm{mL}+$ RvE1 $100 \mathrm{nM}$

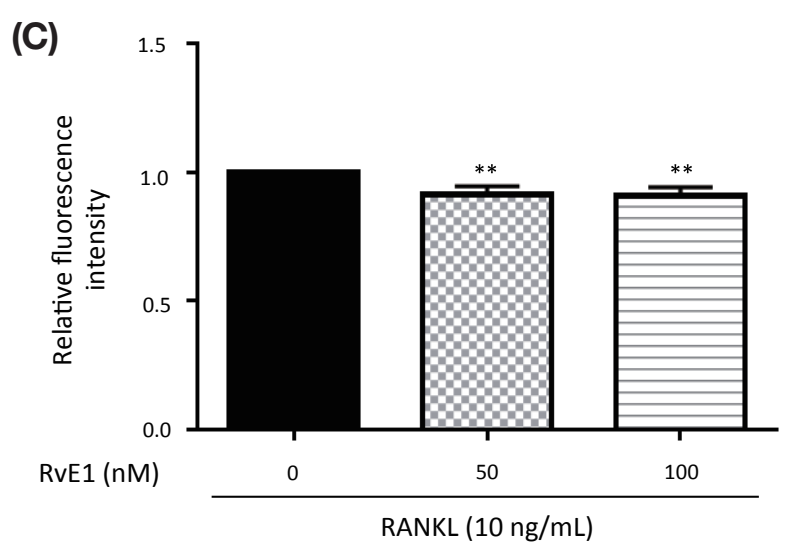

\section{Statistical analysis}

The experimental data were analyzed using Graphpad Prism 6 (Graphpad Software, San Diego, CA). All experiments were conducted separately at least three times, and all data are presented as the mean \pm SD. Statistically significant differences were assessed by analysis of variance (followed by Bonferroni multiple comparisons test) or Student's $t$-test with P-values $<0.05$ considered significant.

\section{RESULTS}

\section{RvE1 reduced the number of TRAP-positive osteo-} clast-like RAW264.7 cells

The CCK- 8 assay confirmed that any effects of RvE1 on osteoclastogenesis would not be due to the cytotoxicity of this compound, since no change in cell viability was noted in RAW264.7 cells and MC3T3-E1 cells treated with RvE1 (data not shown).

TRAP-positive osteoclast-like cells were observed
(B)

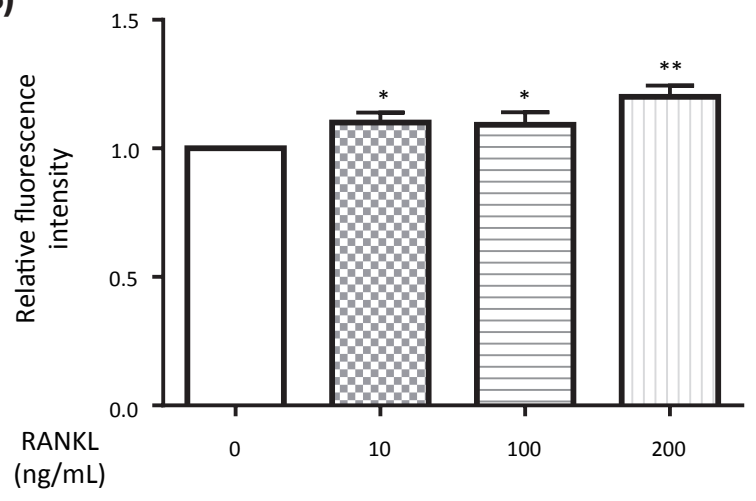

Fig. 2. Effects of RvE1 on osteoclastic bone resorption in RAW264.7 cells. RAW264.7 cells were cultured with 50 or 100 nM RvE1 in the presence of different doses (10, 100, $200 \mathrm{ng} / \mathrm{mL}$ ) of RANKL for 6 days. Resorption pits were observed on day 7 in the conditioned medium treated with $10 \mathrm{ng} / \mathrm{mL}$ RANKL, whereas no resorption pit was observed in the medium without RANKL. However, the area of resorption pits was decreased by treatment with $100 \mathrm{nM} \mathrm{RvE1}$. Original magnification, $\times 200$ (A). The levels of fluorescence intensity, representing the activity of osteoclast generation, of the supernatant in the presence of 10 , 100 and $200 \mathrm{ng} / \mathrm{mL}$ RANKL were determined (B). The levels of fluorescence intensity of the supernatant treated with 50 or $100 \mathrm{nM}$ RvE1 in the presence of $10 \mathrm{ng} / \mathrm{mL}$ RANKL were determined (C). Data are expressed as the mean $\pm \mathrm{SD}(n=3)$. $* P<0.05$, $* * P<0.01$ versus control $(\mathbf{B}) .{ }^{*} P<0.01$ versus RANKL $(\mathbf{C})$. RANKL, receptor activator of nuclear factor- $\varkappa \mathrm{B}$ ligand; RvE1, resolvin E1.

when RAW264.7 cells were cultured in the presence RANKL, and the number of positive cells increased in a dose-dependent manner. However, the number of TRAP-positive cells decreased in the conditioned medium treated with both $100 \mathrm{nM} \mathrm{RvE1}$ and RANKL (Fig. $1 \mathrm{~A})$, representing a statistically significant reduction compared to those detected with 50 and $100 \mathrm{ng} / \mathrm{mL}$ RANKL alone (Fig. 1B).

\section{RvE1 suppressed osteoclastic bone resorption in RAW264.7 cells}

To assess the effects of RvE1 on bone resorption, RAW264.7 cells were cultured with or without RvE1 in the presence of different doses (10, 100 and $200 \mathrm{ng} / \mathrm{mL}$ ) of RANKL. Resorption pits were observed in the conditioned medium of RAW264.7 cells treated with $10 \mathrm{ng} /$ mL RANKL, which were not detected in the medium without RANKL (Fig. 2A). The fluorescence intensity, representing the activity of osteoclast generation, sig- 
(A)

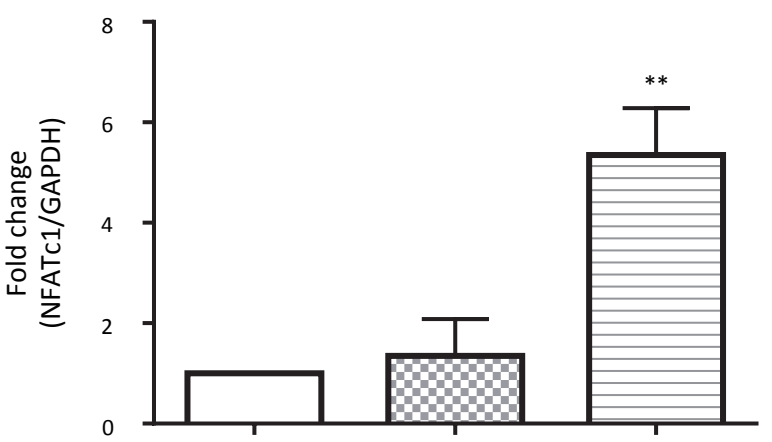

Time (h)

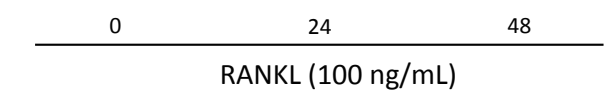

(C)

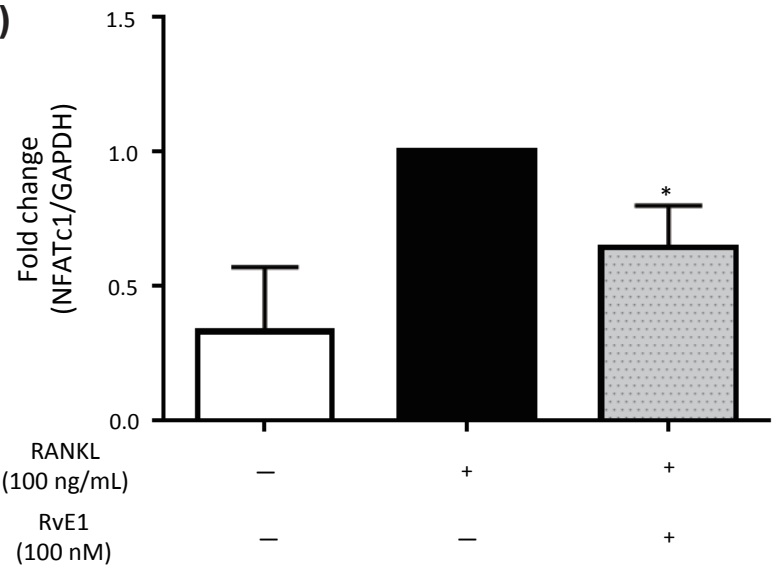

(E)

NFATc1
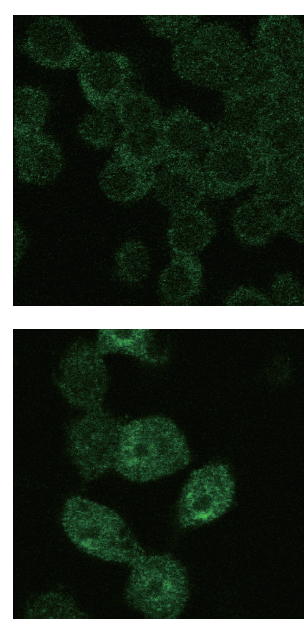

RANKL $50 \mathrm{ng} / \mathrm{mL}$

RANKL $50 \mathrm{ng} / \mathrm{mL}$

+ RvE1 $100 \mathrm{nM}$

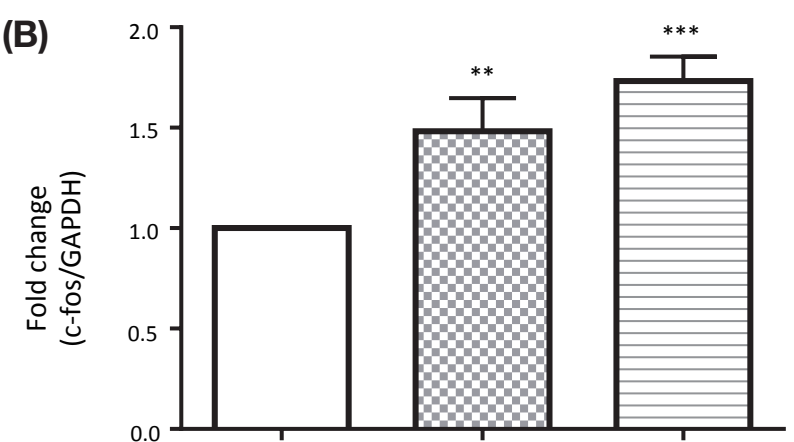

Time (h)

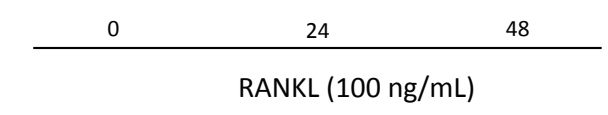

(D)

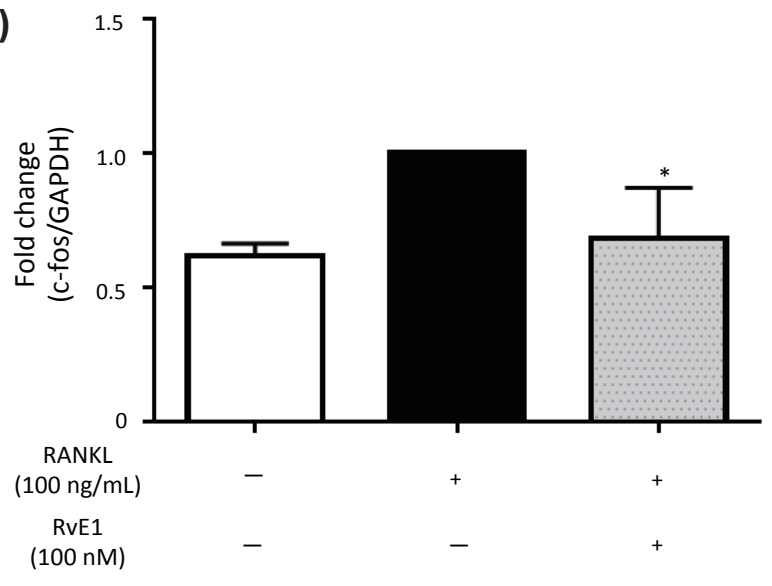

Fig. 3. Effects of RvE1 on RANKL-induced NFATc1 and c-fos mRNA expression, and NFATcl translocation in RAW264.7 cells. RAW264.7 cells were pretreated with RvE1 and then stimulated with $100 \mathrm{ng} / \mathrm{mL}$ RANKL for 24 or $48 \mathrm{~h}$, and the expression levels of NFATcl and c-fos mRNA were determined by real-time PCR (A and B). The expression levels of mPGES-1 and COX-2 mRNA in the presence or absence of $100 \mathrm{ng} / \mathrm{mL}$ RANKL and/or $100 \mathrm{nM} \mathrm{RvE} 1$ at $48 \mathrm{~h}$ were determined by real-time PCR (C and $\mathbf{D})$. Data are expressed as the mean $\pm \mathrm{SD}(n=3)$. $* * P<0.01, * * * P<0.001$ versus $0 \mathrm{~h}(\mathbf{A}$ and $\mathbf{B}) . * P<0.05$ versus RANKL $(\mathbf{C}$ and D). RAW264.7 cells were exposed to 50 or $100 \mathrm{ng} / \mathrm{mL}$ RANKL with or without $100 \mathrm{nM} \mathrm{RvE1} \mathrm{for} 48 \mathrm{~h}$. The location of NFATc1 (green) was identified with an immunofluorescence assay. 4,6-diamidino-2-phenylindole (DAPI) was used to label the nuclei (blue). Scale bar $=20 \mu \mathrm{m}$ (E). DAPI, 4',6-diamidino-2-phenylindole; GAPDH, glyceraldehyde-3-phosphate dehydrogenase; NFATc1, nuclear factor of activated T cells c1; RANKL, receptor activator of nuclear factor- $\varkappa \mathrm{B}$ ligand; RvE1, resolvin E1. 
(A)

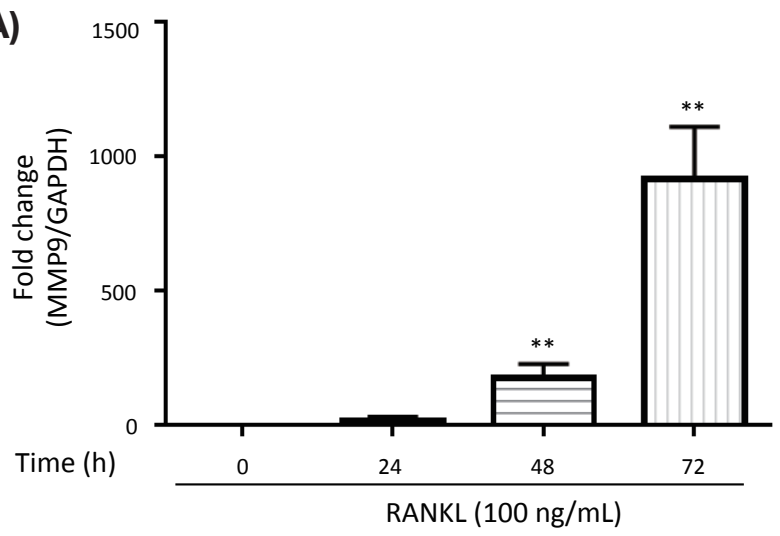

(C)

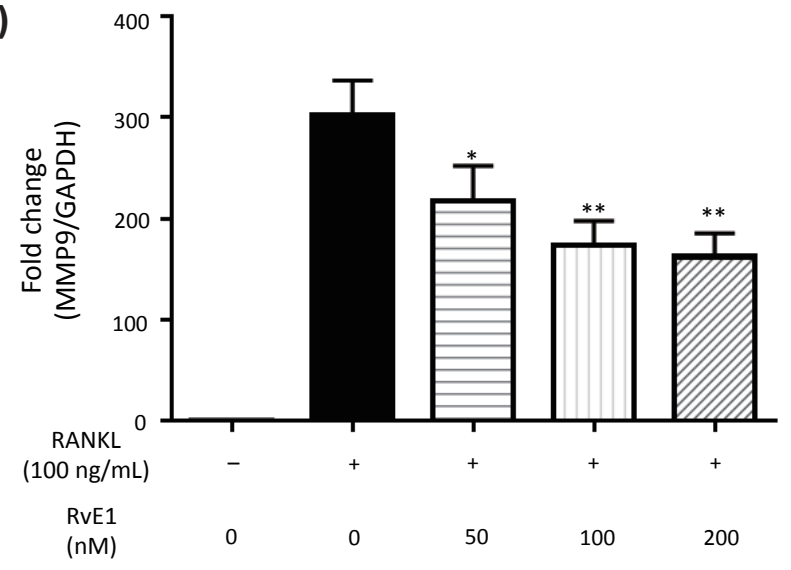

(B)

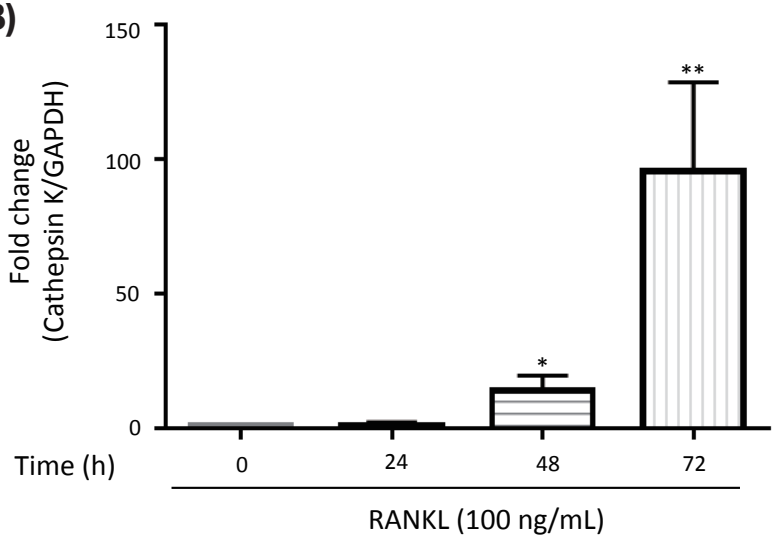

(D)

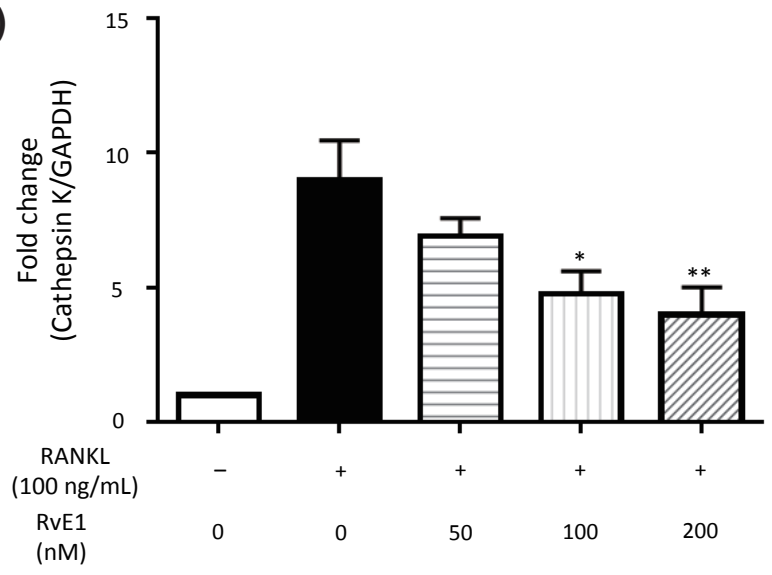

Fig. 4. Effects of RvE1 on RANKL-induced MMP-9 and cathepsin K mRNA expression in RAW264.7 cells.RAW264.7 cells were pretreated with RvE1 and then stimulated with $100 \mathrm{ng} / \mathrm{mL}$ RANKL for 24 or $48 \mathrm{~h}$, and the mRNA expression levels of MMP-9 and cathepsin K were determined by real-time PCR ( $\mathbf{A}$ and $\mathbf{B}$ ). The mRNA expression levels of MMP-9 and cathepsin K in the presence or absence of $100 \mathrm{ng} / \mathrm{mL}$ RANKL and/or $100 \mathrm{nM}$ RvE1 at $48 \mathrm{~h}$ were determined by real-time PCR $(\mathbf{C}$ and $\mathbf{D})$. Data are expressed as the mean $\pm \mathrm{SD}(n$ $=3$ ), $* P<0.05, * * P<0.01$ versus $0 \mathrm{~h}(\mathbf{A}$ and $\mathbf{B}) . * P<0.05$, $* * P<0.01$ versus RANKL (C and $\mathbf{D})$. GAPDH, glyceraldehyde-3-phosphate dehydrogenase; MMP-9, matrix metalloproteinase-9; RANKL, receptor activator of nuclear factor- $\varkappa$ B ligand; RvE1, resolvin E1.

(A)

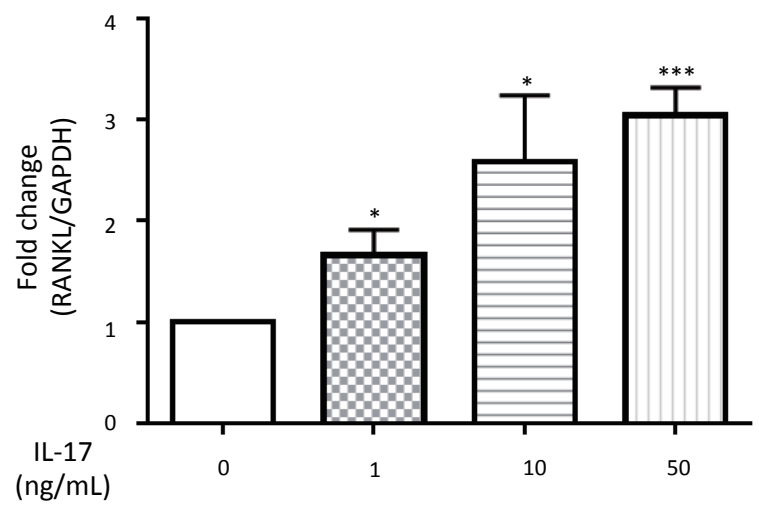

(B)

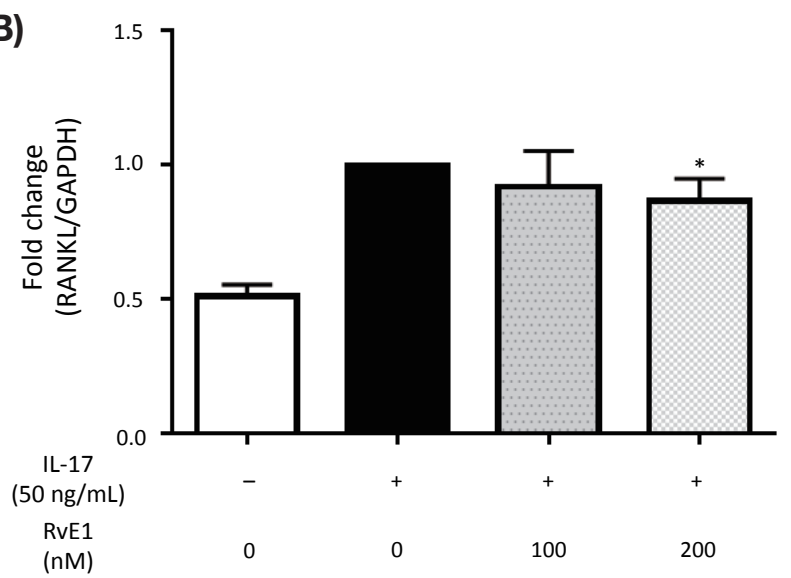

Fig. 5. Effect of RvE1 on IL-17-induced RANKL mRNA expression in MC3T3-E1 cells. MC3T3-E1 cells were cultured in the presence of 1,10 and $50 \mathrm{ng} / \mathrm{mL} \mathrm{IL-17,} \mathrm{and} \mathrm{the} \mathrm{mRNA} \mathrm{expression} \mathrm{level} \mathrm{of} \mathrm{RANKL} \mathrm{was} \mathrm{determined} \mathrm{by} \mathrm{real-time} \mathrm{PCR} \mathrm{(A).} \mathrm{The} \mathrm{cells} \mathrm{were} \mathrm{also}$ cultured with 50, 100 and $200 \mathrm{nM} \mathrm{RvE1}$ in the presence of $50 \mathrm{ng} / \mathrm{mL}$ IL-17. The expression levels of RANKL mRNA in the presence or absence of $50 \mathrm{ng} / \mathrm{mL}$ IL-17 and/or $100 \mathrm{nM}$ RvE1 at $24 \mathrm{~h}$ were determined by real-time PCR. The value of the fold change in mRNA levels of IL-17 alone was normalized as 1. (B). Data are expressed as the mean $\pm \mathrm{SD}(n=3), * P<0.05$, *** $P<0.01$ versus control (A). $* P<$ 0.05 versus IL-17 alone (B). GAPDH, glyceraldehyde-3-phosphate dehydrogenase; IL, interleukin; RANKL, receptor activator of nuclear factor- $\varkappa \mathrm{B}$ ligand; RvE1, resolvin E1. 

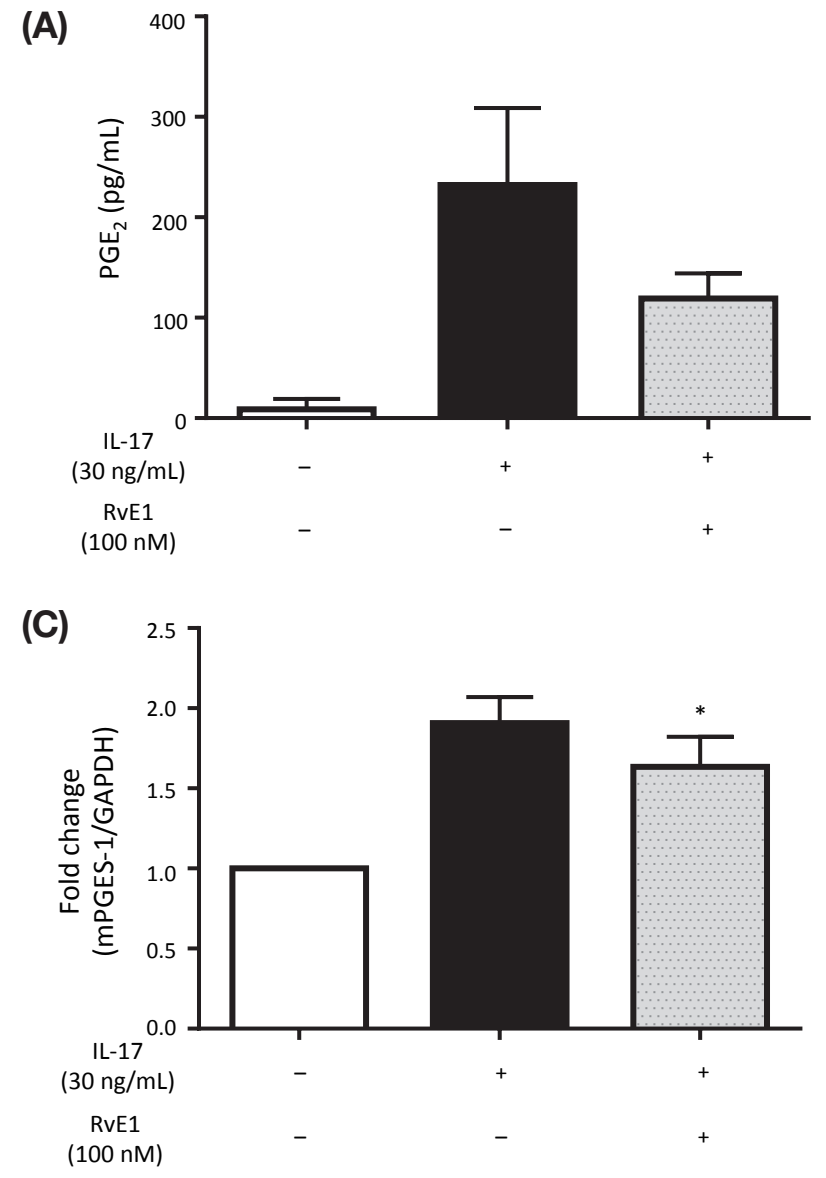

nificantly increased compared to that of the control in a RANKL concentration-dependent manner (Fig. 2B). However, co-treatment with $100 \mathrm{nM}$ RvE1 decreased the area of the resorption Pits (Fig. 2A) and significantly reduced the fluorescent intensity compared to that of the vehicle control (Fig. 2C).

\section{RvE1 suppressed RANKL-induced NFATc1 and c-fos mRNA expression and NFATc1 nuclear trans- location in RAW264.7 cells}

The NFATc1 and c-fos mRNA levels of RAW264.7 cells treated with $100 \mathrm{ng} / \mathrm{mL}$ RANKL increased in a time-dependent manner with a significant increase at $48 \mathrm{~h}$, and at both 24 and $48 \mathrm{~h}$, respectively, compared to $0 \mathrm{~h}$ (Figs. $3 \mathrm{~A}$ and $\mathrm{B})$. However, co-treatment with $100 \mathrm{nM}$ RvE1 significantly reduced the RANKL-induced NFATc1 and c-fos mRNA expression levels compared to those of the vehicle control (Figs. 3C and D). The immunofluorescence assay showed that NFATc1 was mainly localized in the cytoplasm in the control cells, but was distinctly translocated to the nucleus after treatment with $50 \mathrm{ng} /$ $\mathrm{mL}$ RANKL for $48 \mathrm{~h}$; however, the nuclear immunostaining intensity was reduced in the presence of $100 \mathrm{nM}$ RvE1 (Fig. 3E).

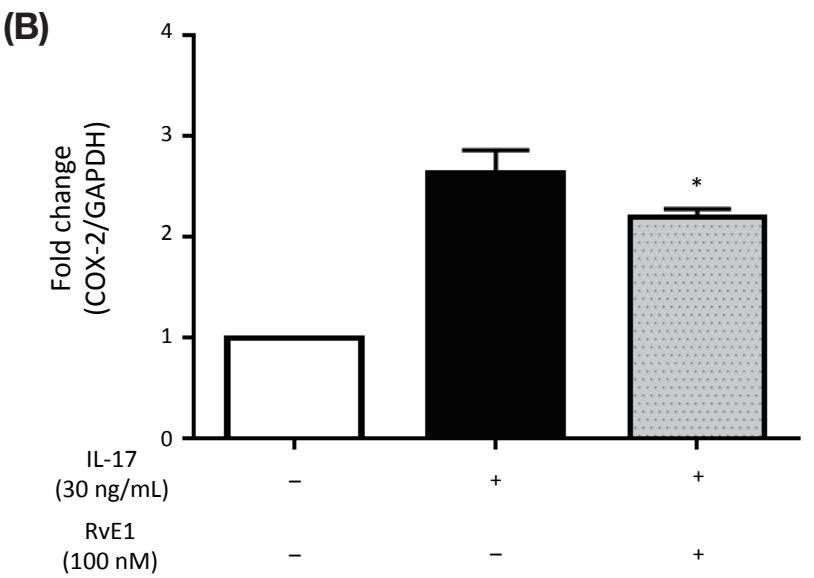

Fig. 6. Effects of RvE1 on IL-17-induced $\mathrm{PGE}_{2}$ production and mRNA expression of COX-2 and mPGES-1 in MC3T3-E1 cells.MC3T3-E1 cells were cultured with $30 \mathrm{ng} / \mathrm{mL}$ IL-17 for $24 \mathrm{~h}$ after pretreatment with $100 \mathrm{nM} \mathrm{RvE} 1$ and the $\mathrm{PGE}_{2}$ production level was determined by ELISA. Data are expressed as the mean $\pm \mathrm{SD}$ ( $n=2$ for control, $n=3$ for $10 \mathrm{ng} / \mathrm{mL} \mathrm{IL-17}$ and IL-17 + $100 \mathrm{nM}$ RvE1); $P=0.075$ versus IL-17 (A). MC3T3-E1 cells were cultured with or without $100 \mathrm{nM}$ RvE1 in the presence of $30 \mathrm{ng} / \mathrm{mL}$ IL-17 for $24 \mathrm{~h}$, and the mRNA expression levels of COX-2 (B) and mPGES-1 (C) were determined by real-time PCR. Data are expressed as the mean $\pm \mathrm{SD}(n=3$ for COX-2, $n=5$ for mPGES-1). $* P<0.05$ versus IL-17. COX-2, cyclooxygenase-2; GAPDH, glyceraldehyde-3-phosphate dehydrogenase; IL, interleukin; mPGES-1, microsomal prostaglandin E synthase-1; $\mathrm{PGE}_{2}$, prostaglandin $\mathrm{E}_{2}$; RvE1, resolvin E1.

\section{RvE1 reduced RANKL-induced MMP-9 and} cathepsin K mRNA expression in RAW264.7 cells

The mRNA expression levels of MMP-9 and cathepsin $\mathrm{K}$ significantly increased at 48 and $72 \mathrm{~h}$ in RAW264.7 cells treated with $100 \mathrm{ng} / \mathrm{mL}$ RANKL compared to $0 \mathrm{~h}$ (Figs. 4A and B). RvE1 significantly reduced RANKL-induced MMP-9 and cathepsin K mRNA expression in a dose-dependent manner compared to the vehicle control (Figs. 4C and D).

\section{RvE1 reduced IL-17-induced RANKL mRNA ex- pression in MC3T3-E1 cells}

After culturing the cells with IL-17 (1, 10 or $50 \mathrm{ng} / \mathrm{mL})$ for $24 \mathrm{~h}$, the RANKL mRNA level was significantly increased in a dose-dependent manner (Fig. 5A). Pretreatment with RvE1 (100 or $200 \mathrm{nM})$ for $24 \mathrm{~h}$ tended to reduce the IL-17-induced RANKL mRNA level in a dose-dependent manner with significant downregulation observed following treatment with $200 \mathrm{nM}$ RvE1 (Fig. 5B). Similarly, the OPG mRNA level was decreased after IL-17 treatment in a dose-dependent manner, and OPG expression was upregulated with RvE1 pretreatment (data not shown). Therefore, RvE1 improved the 
imbalance in the RANKL/OPG ratio, which is likely to induce an inhibitory effect on bone resorption.

\section{RvE1 reduced IL-17-induced PGE2 production and the mRNA expression levels of COX-2 and MPG- ES-1 in MC3T3-E1 cells}

The ELISA results showed that pretreatment of MC3T3-E1 cells with RvE1 inhibited the stimulatory effect of IL-17 on $\mathrm{PGE}_{2}$ production; the $\mathrm{PGE}_{2}$ production levels in the presence of $100 \mathrm{nM}$ RvE1 tended to be reduced compared to those of cells treated with the vehicle control (Fig. 6A). RvE1 treatment also significantly reduced the IL-17-induced expression of COX-2 and mPGES-1 mRNA compared to the vehicle control group (Figs. 6B and C).

\section{DISCUSSION}

RvE1 is a member of the E series of resolvins that are biosynthesized from EPA. ${ }^{11}$ Recent reports identified another member of the $\mathrm{E}$ series of resolvins, called resolvin E2 (RvE2) and resolvin E3 (RvE3). ${ }^{26,27}$ Although Barden and colleagues ${ }^{28}$ showed that synovial fluid RvE2 was negatively associated with pain score in humans, the effects of RvE2 and RvE3 on osteoclasts and osteoblasts were not fully understood. Thus, we investigated RvE1 as a therapeutic agent for RA. With respect to bone metabolism, RvE1 was shown to inhibit osteoclast growth and bone resorption. ${ }^{16}$ Gao and colleagues ${ }^{29}$ reported that RvE1 has a direct bone-preserving function via chemokine-like receptor 1 , which mediates bone preservation in osteoblasts. Moreover, a recent study indicated that RvE1 influenced pain, a major symptom of RA, showing simultaneous anti-inflammatory and analgesic properties in experimental models closely related to translational sites in humans. ${ }^{30}$ These studies have demonstrated the good therapeutic potential of RvE1 in many chronic inflammatory diseases. Indeed, RvE1 (Rx-10001) and its synthetic analog (Rx-10045) are currently under clinical trials for the relief of chronic dry eyes. ${ }^{31}$ The aim of our study was to clarify the effect of RvE1 on osteoclastogenesis and determine its feasibility in the development of a new therapeutic approach to RA.

We showed that RvE1 reduced the number of TRAP-positive osteoclast-like cells, which is consistent with a previous report indicating that RvE1 markedly decreased the number of differentiated osteoclasts induced by macrophage colony-stimulating factor and RANKL in primary osteoclast cultures. ${ }^{16}$

Recently, a new assay method of evaluating the bone resorption activity in RAW264.7 cells was reported based on the measurement of pit formation using calcium phosphate labeled with fluorescent polyanionic mole- cules. ${ }^{25}$ With this method, we found that RvE1 decreased the bone resorption activity in RAW264.7 cells, in line with a previous report showing that RvE1 diminished dentin resorption in vitro. ${ }^{16}$ These results in RAW264.7 cells suggest that RvE1 could inhibit RANKL-induced osteoclastogenesis and bone resorption.

We further found that RvE1 significantly inhibited RANKL-induced NFATc1 and c-fos mRNA expression and the nuclear translocation of NFATc1 from the cytoplasm in RAW264.7 cells, providing a potential mechanism underlying this inhibitory effect of RvE1 on osteoclastogenesis. A previous study showed that RvE1 attenuated the RANKL-induced nuclear translocation of the p50 subunit of NF- $x \mathrm{~B} .{ }^{16} \mathrm{Zhu}$ and colleagues ${ }^{32}$ reported another mechanism of RvE1 in osteoclasts in bone marrow cells of C57BL/6 mice, in which RvE1 inhibits osteoclast fusion through binding NFATc1 to the pivotal fusion protein DC-STAMP, thereby suppressing RANKL-induced NFATc1 nuclear translocation. Another report showed that Bioaggregate, a laboratory-synthesized and calcium silicate-based nanoparticulate cement, also inhibited the translocation of NFATcl and c-fos from the cytoplasm to the nucleus in osteoclast precursor cells, which was determined with immunofluorescence analysis. ${ }^{33}$

Our data indicated that RvE1 inhibited RANKL-induced osteoclastogenesis through suppressing the mRNA expression of NFATc1 and c-fos. NFATc1 is known as a master transcription factor that plays a key role in regulating the expression of several osteoclast-specific genes such as TRAP, cathepsin $\mathrm{K}$ and MMP-9, which are involved in regulating osteoclast differentiation. ${ }^{18}$ Our results suggested that RvE1 significantly inhibited RANKL-induced cathepsin K and MMP-9 mRNA expression by decreasing the translocation of NFATc1 from the cytoplasm to the nucleus.

We further showed that RvE1 might correct the imbalance of RANKL and OPG expression in osteoblasts induced by IL-17 using MC3T3-E1 cells.

$\mathrm{PGE}_{2}$ is well known to be the key mediator of inflammation, pain and joint destruction in RA, and its production is an important target of anti-inflammatory drugs. $\mathrm{PGE}_{2}$ is produced by the conversion of arachidonic acid to prostaglandin $\mathrm{H}_{2}$ by COX-1/COX-2, with the subsequent conversion of prostaglandin $\mathrm{H}_{2}$ to $\mathrm{PGE}_{2}$ by $m$ PGES-1, which is the terminal enzyme in the $\mathrm{PGE}_{2}$ production process at the sites of inflammation, and has an important role in the pathogenesis of RA. ${ }^{34,35} \mathrm{PGE}_{2}$ has several pro-inflammatory effects, including increasing vascular permeability, vasodilation, blood flow and local pyrexia, along with potentiation of pain caused by other agents. Previous studies showed that $\mathrm{PGE}_{2}$ stim- 
ulates osteoclast differentiation through the prostanoid receptors EP4 and EP2 by inducing RANKL production and inhibiting OPG expression. ${ }^{36-38}$ OPG is a soluble decoy receptor for RANKL that prevents it from binding to RANK. RANKL interacts with its receptor, which is expressed on osteoclast precursors, to induce the differentiation and activation of osteoclasts. ${ }^{21} \mathrm{~A}$ recent study showed that EPA and DHA inhibit $\mathrm{PGE}_{2}$-induced RANKL expression in MC3T3-E1 cells. ${ }^{39}$ Similarly, we showed that RvE1 inhibits the IL-17-induced COX-2 and mPGES-1 mRNA expression followed by $\mathrm{PGE}_{2}$ production in MC3T3-E1 cells. These results might indicate that RvE1 indirectly inhibits osteoclastogenesis by reducing IL-17-induced COX-2 and mPGES-1 expression in osteoblasts, suggesting that RvE1, like EPA and DHA, has an anti-inflammatory effect in RA.

We did not examine the effects of RvE1 on the expression of $\mathrm{PGE}_{2}$ receptors in osteoblasts, such as EP4 receptor. However, recent reports showed that $\mathrm{PGE}_{2}$ enhanced osteoclast formation through EP4 receptor activation on osteoblasts. ${ }^{40,41} \mathrm{In}$ addition, the effects of RvE1 on the leukotriene B4 receptor subtype 1 (BLT1) expressed on osteoclasts, identified as receptors for RvE1, ${ }^{42}$ should be further investigated, as a previous study showed that BLT1 mediates the actions of RvE1 on osteoclasts. ${ }^{16}$ Although the major effect of $\mathrm{PGE}_{2}$ on bone resorption is generally considered to occur indirectly via upregulation of RANKL and inhibition of OPG expression in osteoblastic cells, ${ }^{43}$ further study is needed to determine whether the EP4 receptor and BLT1 are therapeutic targets of RvE1. The mechanisms of inflammation in RA are complex. In RA, many pro-inflammatory cytokines including TNF- $\alpha$, IL- $1 \beta$, IL-6, and IL17 increase RANKL expression, leading to an increased osteoclast differentiation and subsequent bone erosions. Several of these cytokines also act synergistically with RANKL in promoting osteoclast differentiation. ${ }^{44}$ Further studies are needed to assess the anti-inflammatory effect of RvE1 in RA.

In conclusion, our results suggest that RvE1 inhibits osteoclastogenesis and bone resorption by suppressing RANKL-induced osteoclast differentiation. The mechanism of action was determined to occur by the downregulation of NFATc1 and c-fos in osteoclasts and suppression of IL-17-induced RANKL expression through the autocrine action of $\mathrm{PGE}_{2}$ in osteoblasts. These findings suggest the potential of RvE1 as a new therapeutic approach to RA, providing the foundation for further preclinical and clinical investigations.

Acknowledgments: This research was partly performed at the Research Center for Bioscience and Technology, Tottori University. We thank Katsumi Higaki (Division of Functional Genomics,
Research Center for Bioscience and Technology, Tottori University, Yonago, Japan) for helpful scientific discussions and technical assistance.

The authors declare no conflict of interest.

\section{REFERENCES}

1 McInnes IB, Schett G. The pathogenesis of rheumatoid arthritis. N Engl J Med. 2011;365:2205-19. PMID: 28617323.

2 Corrado A, Maruotti N, Cantatore FP. Osteoblast Role in Rheumatic Diseases. International journal of molecular sciences. 2017;18. PMID: 28617323.

3 Kotake S, Udagawa N, Takahashi N, Matsuzaki K, Itoh K, Ishiyama S, et al. IL-17 in synovial fluids from patients with rheumatoid arthritis is a potent stimulator of osteoclastogenesis. J Clin Invest. 1999;103:1345-52. PMID: 10225978.

4 Walsh NC, Crotti TN, Goldring SR, Gravallese EM. Rheumatic diseases: the effects of inflammation on bone. Immunol Rev. 2005;208:228-51. PMID: 16313352.

5 Kremer JM, Bigauoette J, Michalek AV, Timchalk MA, Lininger L, Rynes RI, et al. Effects of manipulation of dietary fatty acids on clinical manifestations of rheumatoid arthritis. Lancet. 1985;1:184-7. PMID: 2857265.

6 Caughey GE, Mantzioris E, Gibson RA, Cleland LG, James MJ. The effect on human tumor necrosis factor alpha and interleukin 1 beta production of diets enriched in n-3 fatty acids from vegetable oil or fish oil. Am J Clin Nutr. 1996;63:116-22. PMID: 8604658.

7 Trebble T, Arden NK, Stroud MA, Wootton SA, Burdge GC, Miles EA, et al. Inhibition of tumour necrosis factor-alpha and interleukin 6 production by mononuclear cells following dietary fish-oil supplementation in healthy men and response to antioxidant co-supplementation. The British journal of nutrition. 2003;90:405-12. PMID: 12908901.

8 Calder PC. Session 3: Joint Nutrition Society and Irish Nutrition and Dietetic Institute Symposium on 'Nutrition and autoimmune disease' PUFA, inflammatory processes and rheumatoid arthritis. Proc Nutr Soc. 2008;67:409-18. PMID: 18847518.

9 Goldberg RJ, Katz J. A meta-analysis of the analgesic effects of omega-3 polyunsaturated fatty acid supplementation for inflammatory joint pain. Pain. 2007;129:210-23. PMID: 17335973.

10 Serhan CN. Pro-resolving lipid mediators are leads for resolution physiology. Nature. 2014;510:92-101. PMID: 24899309.

11 Serhan CN, Clish CB, Brannon J, Colgan SP, Chiang N, Gronert K. Novel functional sets of lipid-derived mediators with antiinflammatory actions generated from omega-3 fatty acids via cyclooxygenase 2-nonsteroidal antiinflammatory drugs and transcellular processing. J Exp Med. 2000;192:1197204. PMID: 11034610.

12 Hasturk H, Kantarci A, Ohira T, Arita M, Ebrahimi N, Chiang N, et al. RvE1 protects from local inflammation and osteoclast- mediated bone destruction in periodontitis. FASEB J. 2006;20:401-3. PMID: 16373400.

13 Schwab JM, Chiang N, Arita M, Serhan CN. Resolvin E1 and protectin D1 activate inflammation-resolution programmes. Nature. 2007;869-74. 17568749.

14 Aoki H, Hisada T, Ishizuka T, Utsugi M, Kawata T, Shimizu Y, et al. Resolvin E1 dampens airway inflammation and hyperresponsiveness in a murine model of asthma. Biochem Biophys 
Res Commun. 2008;367:509-15. PMID: 18190790.

15 Seki H, Fukunaga K, Arita M, Arai H, Nakanishi H, Taguchi $\mathrm{R}$, et al. The anti-inflammatory and proresolving mediator resolvin E1 protects mice from bacterial pneumonia and acute lung injury. J Immunol. 2010;184:836-43. PMID: 20007539.

16 Herrera BS, Ohira T, Gao L, Omori K, Yang R, Zhu M, et al. An endogenous regulator of inflammation, resolvin E1, modulates osteoclast differentiation and bone resorption. Br J Pharmacol. 2008;155:1214-23. PMID: 18806821.

17 Grigoriadis AE, Wang ZQ, Cecchini MG, Hofstetter W, Felix R, Fleisch HA, et al. c-Fos: a key regulator of osteoclast-macrophage lineage determination and bone remodeling. Science. 1994;266:443-8. PMID: 7939685.

18 Takayanagi H, Kim S, Koga T, Nishina H, Isshiki M, Yoshida $\mathrm{H}$, et al. Induction and activation of the transcription factor NFATc1 (NFAT2) integrate RANKL signaling in terminal differentiation of osteoclasts. Developmental cell. 2002;3:889901. PMID: 12479813.

19 Gyurko R, Van Dyke TE. The role of polyunsaturated $\omega-3$ fatty acid eicosapentaenoic acid-derived resolvin E1 (RvE1) in bone preservation. Crit Rev Immunol. 2014;34:347-57. PMID: 24941160.

20 Kong YY, Boyle WJ, Penninger JM. Osteoprotegerin ligand: a regulator of immune responses and bone physiology. Immunology today. 2000;21:495-502. PMID:11071528.

21 Boyle WJ, Simonet WS, Lacey DL. Osteoclast differentiation and activation. Nature. 2003;423:337-42. PMID: 12748652.

22 Moseley TA, Haudenschild DR, Rose L, Reddi AH. Interleukin-17 family and IL-17 receptors. Cytokine \& growth factor reviews. 2003;14:155-74. PMID: 12651226.

23 Suda T, Takahashi N, Udagawa N, Jimi E, Gillespie MT, Martin TJ. Modulation of osteoclast differentiation and function by the new members of the tumor necrosis factor receptor and ligand families. Endocrine reviews. 1999;20:345-57. PMID: 10368775.

24 Boeyens JC, Deepak V, Chua WH, Kruger MC, Joubert AM, Coetzee M. Effects of omega3- and omega6-polyunsaturated fatty acids on RANKL-induced osteoclast differentiation of RAW264.7 cells: a comparative in vitro study. Nutrients. 2014;6: 2584-601. PMID: 25010555.

25 Miyazaki T, Miyauchi S, Anada T, Imaizumi H, Suzuki O. Evaluation of osteoclastic resorption activity using calcium phosphate coating combined with labeled polyanion. Analytical biochemistry. 2011;410:7-12. PMID: 21078287.

26 Tjonahen E, Oh SF, Siegelman J, Elangovan S, Percarpio KB, Hong S, et al. Resolvin E2: identification and anti-inflammatory actions: pivotal role of human 5-lipoxygenase in resolvin E series biosynthesis. Chem Biol. 2006;13:1193-202. PMID: 17114001.

27 Isobe Y, Arita M, Matsueda S, Iwamoto R, Fujihara T, Nakanishi $\mathrm{H}$, et al. Identification and structure determination of novel anti-inflammatory mediator resolvin E3, 17,18-dihydroxyeicosapentaenoic acid. J Biol Chem. 2012;287:10525-34. PMID:22275352

28 Barden AE, Moghaddami M, Mas E, Phillips M, Cleland LG, Mori TA. Specialised pro-resolving mediators of inflammation in inflammatory arthritis. Prostaglandins Leukot Essent Fatty Acids. 2016;107:24-9. PMID: 27033423.

29 Gao L, Faibish D, Fredman G, Herrera BS, Chiang N, Serhan $\mathrm{CN}$, et al. Resolvin E1 and chemokine-like receptor 1 mediate bone preservation. J Immunol. 2013;190:689-94. PMID: 23241890.

30 Fonseca FC, Orlando RM, Turchetti-Maia RM, de Francischi
JN. Comparative effects of the omega3 polyunsaturated fatty acid derivatives resolvins E1 and D1 and protectin DX in models of inflammation and pain. Journal of inflammation research. 2017;10:119-33. PMID: 28919798.

31 Hessen M, Akpek EK. Dry eye: an inflammatory ocular disease. Journal of ophthalmic \& vision research. 2014;9:240-50. PMID: 25279127.

32 Zhu M, Van Dyke TE, Gyurko R. Resolvin E1 regulates osteoclast fusion via DC-STAMP and NFATc1. FASEB J. 2013;27:3344-53. PMID: 23629863.

33 Zhang J, Zhu L, Yan P, Peng B. Effect of BioAggregate on Receptor Activator of Nuclear Factor-Kappa B Ligand-induced Osteoclastogenesis from Murine Macrophage Cell Line In Vitro. J Endod. 2015;41:1265-71. PMID: 25975181.

34 Jakobsson PJ, Thoren S, Morgenstern R, Samuelsson B. Identification of human prostaglandin $\mathrm{E}$ synthase: a microsomal, glutathione-dependent, inducible enzyme, constituting a potential novel drug target. Proc Natl Acad Sci U S A. 1999;96:7220-5. PMID: 10377395.

35 Samuelsson B, Morgenstern R, Jakobsson PJ. Membrane prostaglandin E synthase-1: a novel therapeutic target. Pharmacol Rev. 2007;59:207-24. PMID: 17878511.

36 Suzawa T, Miyaura C, Inada M, Maruyama T, Sugimoto Y, Ushikubi F, et al. The role of prostaglandin $\mathrm{E}$ receptor subtypes (EP1, EP2, EP3, and EP4) in bone resorption: an analysis using specific agonists for the respective EPs. Endocrinology. 2000;141:1554-9. PMID: 10746663.

37 Nukaga J, Kobayashi M, Shinki T, Song H, Takada T, Takiguchi T, et al. Regulatory effects of interleukin-lbeta and prostaglandin E2 on expression of receptor activator of nuclear factor-kappaB ligand in human periodontal ligament cells. J Periodontol. 2004;75:249-59. PMID: 15068113.

38 Liu XH, Kirschenbaum A, Yao S, Levine AC. Cross-talk between the interleukin- 6 and prostaglandin $E(2)$ signaling systems results in enhancement of osteoclastogenesis through effects on the osteoprotegerin/receptor activator of nuclear factor-\{kappa\}B (RANK) ligand/RANK system. Endocrinology. 2005;146:1991-8. PMID: 15618359.

39 Poulsen RC, Wolber FM, Moughan PJ, Kruger MC. Long chain polyunsaturated fatty acids alter membrane-bound RANK-L expression and osteoprotegerin secretion by MC3T3-E1 osteoblast-like cells. Prostaglandins Other Lipid Mediat. 2008;85:42-8. PMID: 18077200.

40 Mano M, Arakawa T, Mano H, Nakagawa M, Kaneda T, Kaneko H, et al. Prostaglandin E2 directly inhibits bone-resorbing activity of isolated mature osteoclasts mainly through the EP4 receptor. Calcif Tissue Int. 2000;67:85-92. PMID: 10908419.

41 Sakuma Y, Tanaka K, Suda M, Yasoda A, Natsui K, Tanaka I, et al. Crucial involvement of the EP4 subtype of prostaglandin E receptor in osteoclast formation by proinflammatory cytokines and lipopolysaccharide. J Bone Miner Res. 2000;15:21827. PMID: 10703923.

42 Arita M, Bianchini F, Aliberti J, Sher A, Chiang N, Hong S, et al. Stereochemical assignment, antiinflammatory properties, and receptor for the omega-3 lipid mediator resolvin E1. J Exp Med. 2005;201:713-22. PMID: 15753205.

43 Blackwell KA, Raisz LG, Pilbeam CC. Prostaglandins in bone: bad cop, good cop? Trends in endocrinology and metabolism: TEM. 2010;21:294-301. PMID: 20079660.

44 Brennan FM, McInnes IB. Evidence that cytokines play a role in rheumatoid arthritis. J Clin Invest. 2008;118:3537-45. PMID: 18982160 